\title{
Diaphragmatic Function in Infants with Surgically Corrected Anomalies
}

\author{
GABRIEL DIMITRIOU, ANNE GREENOUGH, VASILIKI KAVVADIA, MARK DAVENPORT, \\ KYPROS H. NICOLAIDES, JOHN MOXHAM, AND GERRARD F. RAFFERTY
}

Department of Child Health [G.D., A.G., V.K., G.F.R.]; Department of Paediatric Surgery [M.D.], Department of Respiratory Medicine [J.M.], and the Harris Birthright Research Centre for Fetal Medicine [K.H.N.], Guy's, King's, and St Thomas' School of Medicine, Children Nationwide Regional Neonatal Intensive Care Centre, King's College London and King's College Hospital National Health Service Trust, London SE5 9RS, United Kingdom

\begin{abstract}
Infants with surgically correctable anomalies, abdominal wall defects (AWD) or congenital diaphragmatic hernia (CDH) may have poor postnatal diaphragmatic function, because the low intra-abdominal pressure experienced by such patients in utero could result in impaired diaphragmatic development. Our objective was to compare postoperative diaphragmatic function of infants with $\mathrm{CDH}$ or AWD to that of gestational age-matched controls. Diaphragmatic function was assessed by measurement of the transdiaphragmatic pressure and maximum inspiratory pressure at the mouth generated during crying against an occlusion. In addition, the transdiaphragmatic pressure produced by unilateral and/or bilateral magnetic stimulation of the phrenic nerves (TwPdi) was examined. Lung volume was assessed by measurement of functional residual capacity (FRC) using a helium gas dilution technique. Ten infants with $\mathrm{CDH}, 26$ with AWD infants (19 gastroschisis, seven exomphalos), and 36 gestational age-matched controls were studied. Compared with their matched controls, the eight $\mathrm{CDH}$ infants with left-sided defects had significantly lower left $(p<0.01)$ and right $(p<$ $0.05)$ TwPdi and FRC $(p<0.01)$, and the gastroschisis infants, but not those with exomphalos, had significantly lower left and right TwPdi $(p<0.05)$. There were no significant differences in transdiaphragmatic pressure and maximum inspiratory pressure
\end{abstract}

\section{ABSTRACT}

at the mouth between the CDH or AWD infants and the controls. Diaphragmatic function postoperatively is impaired in infants with $\mathrm{CDH}$ or gastroschisis. (Pediatr Res 54: 502-508, 2003)
AMS, anterior magnetic stimulation
AWD, anterior wall defects
CDH, congenital diaphragmatic hernia
cPdi, transdiaphragmatic pressure during crying
cPgas, gastric pressure during crying
cPoes, esophageal pressure during crying
FRC, functional residual capacity
NAS, neonatal abstinence syndrome
NICU, neonatal intensive care unit
Pdi, transdiaphragmatic pressure
Pgas, gastric pressure
Poes, esophageal pressure
Pimax, maximum inspiratory pressure at the mouth
REM, rapid eye movement
TPN, total parenteral nutrition
TTN, transient tachypnea of the newborn
TwPdi, transdiaphragmatic pressure produced by unilateral and/or bilateral magnetic stimulation of the phrenic nerves

Surgically correctable birth defects, $\mathrm{CDH}$, and AWD are common and associated with respiratory morbidity. Infants with $\mathrm{CDH}$ can suffer bronchopulmonary dysplasia and recurrent infections $(1,2)$ and, in both conditions, pulmonary function abnormalities are demonstrated outside the perinatal period (1-4). These problems may be due to poor antenatal lung

Received June 27, 2002; accepted February 10, 2003.

Correspondence: A. Greenough, Children Nationwide Regional Neonatal Intensive Care Centre, 4th floor, Golden Jubilee Wing, King's College Hospital, London SE5 9RS, United Kingdom; e-mail: anne.greenough@kcl.ac.uk

G.D. was supported by the Children Nationwide Medical Research Fund and V.K. by the South Thames Regional Health Authority Research and Development Directorate.

DOI: 10.1203/01.PDR.0000081299.22005.F0 growth. Abnormal diaphragmatic function impairs antenatal lung growth (5-8) and we hypothesize that infants with $\mathrm{CDH}$ or AWD may have abnormal diaphragmatic development and function. $\mathrm{CDH}$ and AWD infants experience low intraabdominal pressure in utero, as viscera are extra-abdominal. Repetitive (9) or passive (10) stretch of skeletal muscles is important to increase myofiber diameter and area. The ipsilateral diaphragm of a CDH infant would be expected to function poorly immediately after operative repair but, if our hypothesis is correct, then the contralateral diaphragm function would also be reduced because of the low intra-abdominal pressure in utero. Diaphragmatic function in neonates has previously been assessed by measurement of cPdi (11). That test, however, is 
volitional and hence the results could be variable. Diaphragmatic force production can be assessed using a nonvolitional test, that is magnetic stimulation of the phrenic nerves. We (12) have previously demonstrated that this technique is easily applied, well tolerated, and reproducible in infants. The aim, therefore, of this study was to test our hypothesis by comparing the diaphragmatic function (assessed using volitional and nonvolitional tests) of infants with surgically correctable AWD or $\mathrm{CDH}$ to that of gestational age-matched controls.

\section{METHODS}

During a 3-y period, infants who had had a CDH or AWD surgically repaired at least $1 \mathrm{wk}$ previously were eligible for entry into this study. Each infant, whose parents gave written consent, was then matched for gestational age to a control infant. The controls had all been admitted to the NICU but, at the time of measurement, had no ongoing respiratory problems or supplementary oxygen requirements for at least $4 \mathrm{~d}$. The study was approved by the hospital's Research Ethics Committee and the parents of all the infants who participated in the study gave informed, written consent.

Diaphragm function was assessed, once the $\mathrm{CDH}$ and $\mathrm{AWD}$ infants no longer required either mechanical ventilation or continuous positive airway pressure, by measurement of the maximum cPdi and Pimax generated during crying against an occlusion. In addition, TwPdi was examined (12). No sedation was given and the infants were studied in the supine position at least $1 \mathrm{~h}$ after a feed. Poes, Pgas, and transdiaphragmatic pressures were measured using balloon catheters (Morgan Medical-UK, Rainham, U.K.) placed in the lower esophagus and stomach. Each catheter was $116.5 \mathrm{~cm}$ long with an interior diameter of $1 \mathrm{~mm}$. The esophageal balloon was $2.9 \mathrm{~cm}$ long and had a circumference of $1.2 \mathrm{~cm}$ when uninflated and the gastric balloon was $4.2 \mathrm{~cm}$ long and had a circumference of 2 $\mathrm{cm}$ when uninflated. Both balloons had a wall thickness of approximately $0.075 \mathrm{~mm}$. Mouth pressure was measured from a side port of a pneumotachograph (Mercury F10L, GM Instruments, Kilwinning, Scotland) inserted into a facemask. The total dead space of the pneumotachograph and facemask in situ was approximately $4.5 \mathrm{~mL}$. Mouth pressure, Poes, and Pgas were measured using differential pressure transducers (MP45 range $\pm 100 \mathrm{~cm} \mathrm{H}_{2} \mathrm{O}$, Validyne, Northridge CA, U.S.A.). The pressure signals were displayed in real time on a computer (Macintosh Centris 650, Apple Computer Company, Cupertino, CA, U.S.A.) running Labview 2.2 software (National Instruments, Austin, TX, U.S.A.) with analog to digital sampling at $100 \mathrm{~Hz}$ (NB-MI016, National Instruments). Pdi was obtained by online subtraction of Poes from Pgas. Accurate measurement of transdiaphragmatic pressure was ensured by correct positioning of the balloon catheters. Initially, both the esophageal and gastric balloon catheters were placed in the stomach as indicated by positive pressure swings during inspiration. The esophageal catheter was then withdrawn until a negative pressure deflection was recorded during inspiration. A temporary occlusion of the airway was then effected by occluding the distal end of the pneumotachograph with the face mask placed over the infant's nose and mouth. The esophageal balloon catheter was confirmed to be correctly sited when the pressure recorded by the esophageal balloon catheter was $90-110 \%$ of the pressure recorded inside the face mask (13). The gastric balloon catheter was assumed to be correctly sited when there were positive pressure swings during inspiration.

To measure Pimax and cPdi, the facemask was held firmly over the infant's nose and mouth during crying. The airway was occluded at end expiration, that is, at the end of a crying effort. The infants were observed for evidence of chest wall distortion during occlusions and none was witnessed. The timing of the occlusions was determined by observation of the real-time display of the flow signal. Pimax was measured from the pressure changes during crying. Pdi was obtained online by substraction of Poes from Pgas. The baselines of cPdi, Poes during crying (cPoes), and Pgas during crying (cPgas) were identified during quiet breathing. Two or three sets of five or more occlusions, giving at least 10 airway occlusions, were performed and the maximum Pimax and cPdi achieved for an individual noted. The mean intracoefficients of variation of cPdi and Pimax were 7\% and 12\%, respectively.

AMS was performed using a 90-mm circular coil (Magstim Co., Whitland Dyfed, U.K.) (Fig. 1). A section of the face of the stimulating coil was placed over the phrenic nerve on the anterior aspect of the neck at the posterior border of the sternomastoid muscle at the level of the cricoid cartilage. Bilateral stimulation was performed by discharging two magnetic coils simultaneously. A Magstim 200 (high-power) magnetic stimulator (Magstim Co.) was used to power the magnetic coils. The phrenic nerves were stimulated at end expiration at maximum stimulator output. At least 10 separate, single stimulations were performed on each side or bilaterally. Right and left unilateral and/or bilateral stimulations were performed on each infant. End expiratory Poes was used as an indicator of lung volume relative to FRC, and AMS was only performed when Poes was at its resting baseline FRC value. Only twitches occurring at end expiration, as indicated by Pdi, Poes, and Pgas waveforms, were analyzed. At least five stimulations were suitable for analysis on each occasion. The data are reported as the mean of at least five satisfactory twitches. Sleep state was not formally assessed, but infants were only studied during periods of quiet sleep, when rapid eye movements and gross body movements were absent, or when awake. The infants were observed for evidence of chest wall distortion during the measurements, none was observed. To avoid twitch potentiation of the diaphragm, there was a period of $10 \mathrm{~min}$ of quiet breathing before stimulation was commenced and a 20-s interval between each twitch.

Lung volume was assessed by measurement of FRC using a helium gas dilution technique and a specially designed infant

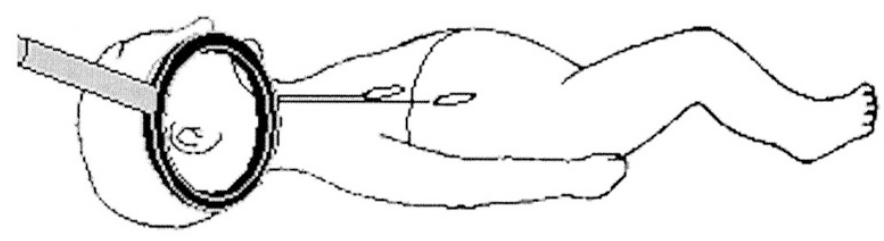

Figure 1. Diagrammatic representation of the 90-mm magnetic stimulating coil positioned for unilateral AMS of the phrenic nerve. 
circuit with a volume of $95 \mathrm{~mL}$ (14). The FRC system (Series 7700, Equilibrated Biosystems Inc, Melville, NY, U.S.A.) contained a rebreathing bag, connected to a three-way valve and face mask from which the infant breathed, and a helium analyzer with a digital display. Helium concentration was recorded before and at 15 -s intervals during the measurement. Equilibration was assumed when there had been no change in the helium concentration over $30 \mathrm{~s}$. The initial and equilibration helium concentrations were used in the calculation of FRC, which was corrected for oxygen consumption, assumed to be $7 \mathrm{~mL} / \mathrm{kg} / \mathrm{min}$ (15), and body temperature and pressure saturated conditions. FRC was estimated twice in each infant, with an interval of 10 min between measurements. An individual's FRC was the mean of the paired measurements and related to body weight. The coefficient of repeatability of FRC measurements in spontaneously breathing infants is $3.9 \mathrm{~mL} / \mathrm{kg}$ (16). The median FRC of term infants is $30 \mathrm{~mL} / \mathrm{kg}$ (range, $24-36 \mathrm{~mL} / \mathrm{kg}$ ) (4).

Statistical analysis. The data were tested for normality using the Kolmogorov-Smirnov and D'Agostino skewness tests. Accordingly, differences were assessed for statistical significance using the Mann-Whitney $U$ test. The StatView 5.0 package (SAS Inc., Cary, NC, U.S.A.) was used.

Patients. All of the infants with surgically correctable anomalies had been diagnosed antenatally, at the latest, by $20 \mathrm{wk}$ of gestation. All were delivered, underwent surgical repair, and received intensive care at King's College Hospital. During the 3-y period, 16 infants with $\mathrm{CDH}$ were consecutively admitted to the NICU at $\mathrm{KCH}$. Three infants died postoperatively and three parents did not consent for their infants to take part in the study. The CDH group, therefore, comprised 10 infants (six male), eight of whom had left-sided defects (Table 1). The CDH infants underwent surgery at a median age of 3.5 (range, 2-6) d after a period of preoperative stabilization. Three infants with large diaphragmatic defects had surgical closure with expanded polytetrafluoroethylene patch (Gore-Tex, WL Gore, Flagstaff, AZ, U.S.A.). None of the infants required either high-frequency oscillation or extracorporeal membrane oxygenation, but two received inhaled nitric oxide preoperatively. The median duration of ventilation of the $\mathrm{CDH}$ infants was 8 (range, 4-54) d. The infants were studied at a median of 16 (range, 7-46) d after surgical repair. At the time of study, two infants were still dependent on supplementary oxygen. The diagnoses on admission to the NICU of their matched controls (eight male) were meconium aspiration syndrome $(n=1)$, TTN $(n=2)$, hypoglycemia $(n=2)$, birth depression $(n=3)$, infection $(n=1)$, and NAS $(n=1)$.

During the study period, 40 infants with AWD (28 with gastroschisis) were consecutively admitted to the NICU. Parental consent was not obtained in eight cases (seven gastroschisis) and two infants with gastroschisis and one with exomphalos were too unwell to be tested; one infant with gastroschisis subsequently died. Two infants with exomphalos had only minor defects and thus were not included in the study. One infant with exomphalos became agitated when studied and the procedure was discontinued. Results are therefore reported on 19 infants with gastroschisis (nine male) and seven infants with exomphalos (two male) and their gestational age-matched controls (11 male controls for the gastroschisis infants, four male controls for the exomphalos infants) (Table 2). Primary

Table 1. Comparison of the CDH infants who had left-sided defects and their matched controls

\begin{tabular}{lccc}
\hline \multicolumn{1}{c}{$n$} & CDH 8 & Controls 8 & $p$ \\
\hline Gestational age (weeks) & $39(37-41)$ & $39(37-42)$ & $\mathrm{ns}$ \\
Birthweight (kg) & $3.210(2.830-3.496)$ & $3.131(2.510-4.133)$ & $\mathrm{ns}$ \\
PCA (weeks) & $42(39-46)$ & $41(37-43)$ & $\mathrm{ns}$ \\
Postnatal age (days) & $18.5(10-51)$ & $7(1-26)$ & 0.01 \\
cPdi ( $\left.\mathrm{cmH}_{2} \mathrm{O}\right)$ & $54.3(40.2-79.3)$ & $69.1(46.0-100.9)$ & 0.093 \\
Pimax $\left(\mathrm{cmH}_{2} \mathrm{O}\right)$ & $45.4(20.5-57.3)$ & $65.8(37.3-83.2)$ & 0.068 \\
TwPdi $\left(\mathrm{cmH}_{2} \mathrm{O}\right):$ & & & \\
Left & $3.5(1.4-4.5)$ & $5.2(4.4-7.2)$ & 0.0022 \\
Right & $4.0(1.6-5.3)$ & $13.1(7.9-6.8)$ & 0.045 \\
Bilateral & $8.3(6.0-9.7)$ & $25(23-30)$ & 0.055 \\
FRC (ml/kg) & $23(18-25)$ & & 0.0078 \\
\hline
\end{tabular}

Data are demonstrated as median (range).

Table 2. Comparison of the gastroschisis infants and their matched controls

\begin{tabular}{lccc}
\hline \multicolumn{1}{c}{$n$} & Gastroschisis 19 & Controls 19 & $p$ \\
\hline Gestational age (weeks) & $37(27-39)$ & $36(27-42)$ & $\mathrm{ns}$ \\
Birthweight (kg) & $2.576(0.940-3.692)$ & $2.800(0.952-4.634)$ & $\mathrm{ns}$ \\
PCA (weeks) & $40.1(36.9-43.9)$ & $38.7(33.1-42.7)$ & 0.052 \\
Postnatal age (days) & $24(11-73)$ & $8(1-82)$ & \\
cPdi $\left(\mathrm{cmH}_{2} \mathrm{O}\right)$ & $61.6(41.1-79.2)$ & $61.7(30.3-100.9)$ & $\mathrm{ns}$ \\
Pimax $\left(\mathrm{cmH}_{2} \mathrm{O}\right)$ & $43.9(21.5-68.2)$ & $53.3(27.8-83.2)$ & $\mathrm{ns}$ \\
TwPdi $\left(\mathrm{cmH}_{2} \mathrm{O}\right):$ & & & \\
Left & $3.7(2.2-5.8)$ & $4.9(2.5-7.2)$ & 0.041 \\
Right & $3.6(2.5-4.5)$ & $4.2(2.6-6.8)$ & 0.017 \\
Bilateral & $5.5(3.5-14.6)$ & $9.3(4.0-16.7)$ & 0.058 \\
FRC (ml/kg) & $25(19-33)$ & $25(23-35)$ & $\mathrm{ns}$ \\
\hline
\end{tabular}

Data are demonstrated at median (range). 
closure of the anterior wall defect was undertaken whenever possible, otherwise a thin layer silo was created and staged closure undertaken. The AWD infants were ventilated for a median of 5 (range, 0.5-35) d. The infants were studied at a median of 20 (range, 9-72) d after final surgical repair. At the time of study, two exomphalos and no gastroschisis infants were oxygen dependent. The diagnoses on admission to the NICU of their matched controls were meconium aspiration syndrome $(n=1)$, TTN $(n=4)$, hypoglycemia $(n=6)$, birth depression $(n=5)$, prematurity $(n=4)$, rhesus isoimmunization $(n=1)$, infection $(n=4)$, and NAS $(n=1)$.

\section{RESULTS}

Magnetic stimulation was well tolerated by all the infants studied and measurements of TwPdi obtained in all patients. The median left $(p<0.01)$ and right $(p<0.05)$ TwPdi (Fig. $2)$ and FRC $(p<0.01)$ of the CDH infants with left-sided defects were lower than those of their controls, but there were no significant differences in the Pimax and cPdi of the two groups (Table 1). The two infants with right-sided congenital diaphragmatic defects had left TwPdi of 7.3 and $5.0 \mathrm{~cm} \mathrm{H}_{2} \mathrm{O}$, respectively, right TwPdi of 4.4 and $1.7 \mathrm{~cm} \mathrm{H}_{2} \mathrm{O}$, respectively and their FRC were 15.3 and $24.1 \mathrm{~mL} / \mathrm{kg}$, respectively. In addition, the second patient had a bilateral TwPdi of $5.4 \mathrm{~cm}$ $\mathrm{H}_{2} \mathrm{O}$ and cPdi of $43.2 \mathrm{~cm} \mathrm{H}_{2} \mathrm{O}$. The gastroschisis infants had significantly lower left and right TwPdi $(p<0.05)$ (Fig. 3) than their matched controls (Table 2), but had similar cPdi, Pimax, and FRC results. None of the results of the exomphalos infants differed significantly from their matched controls (Table 3 ).

\section{DISCUSSION}

We have demonstrated that diaphragm function, as assessed by measurement of TwPdi, was poorer in the $\mathrm{CDH}$ and gas-

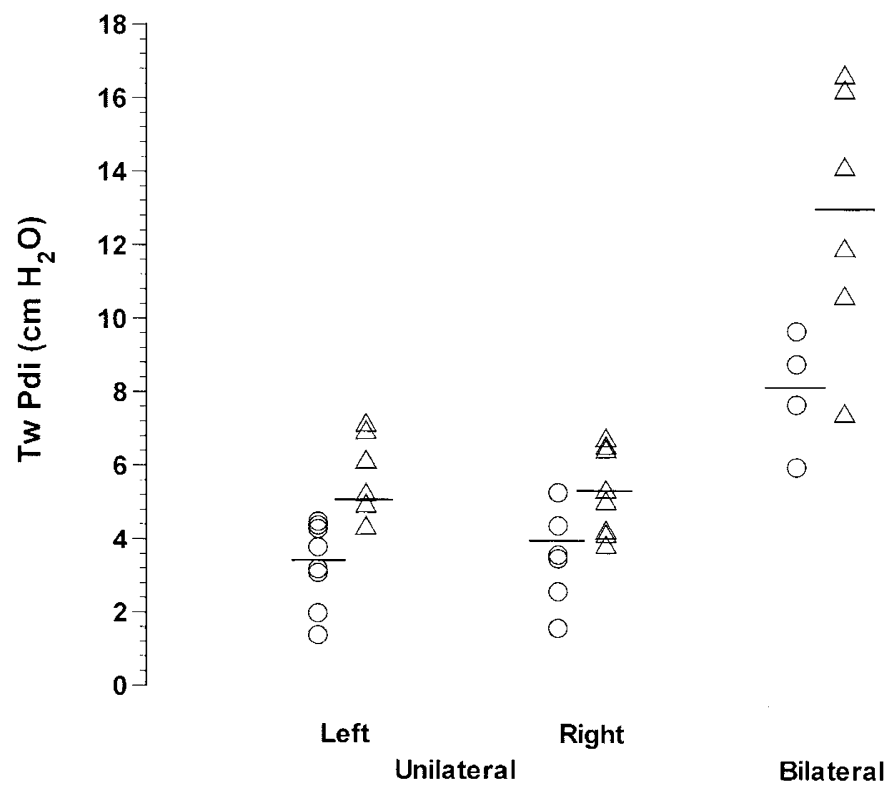

Figure 2. Individual data of left and right unilateral and bilateral TwPdi in infants with $\mathrm{CDH}$ who had left-sided defect (circles) and their matched controls (triangles). The horizontal lines represent the median of each group.

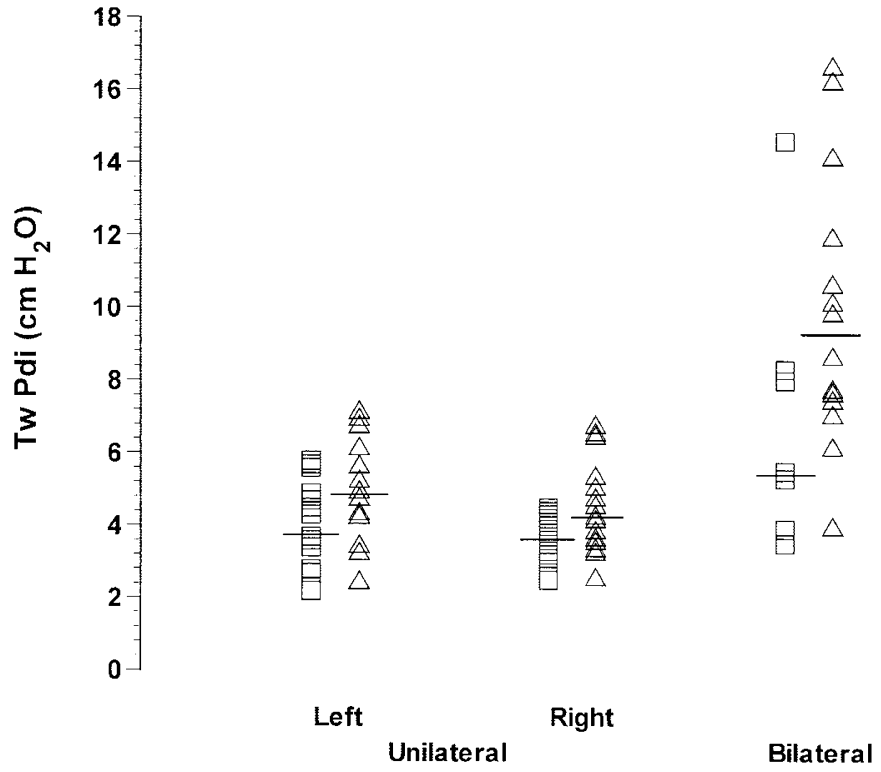

Figure 3. Individual data of left and right unilateral and bilateral TwPdi in infants with gastroschisis (squares) and their matched controls (triangles). The horizontal lines represent the median of each group.

Table 3. Comparison of the exomphalos infants and their matched controls

\begin{tabular}{lccc}
\hline \multicolumn{1}{c}{$n$} & \multicolumn{1}{c}{ Exomphalos 7} & Controls 7 & $p$ \\
\hline Gestational age (weeks) & $35(33-41)$ & $36(32-42)$ & $\mathrm{ns}$ \\
Birthweight (kg) & $2.520(2.176-3.770)$ & $2.800(1.762-3.900)$ & $\mathrm{ns}$ \\
PCA (weeks) & $38.9(34.7-47.3)$ & $36.7(33.1-42.7)$ & $\mathrm{ns}$ \\
Postnatal age (days) & $27(12-58)$ & $6(3-26)$ & 0.015 \\
cPdi $\left(\mathrm{cmH}_{2} \mathrm{O}\right)$ & $51.7(34.1-75.6)$ & $61.5(43.3-75.8)$ & $\mathrm{ns}$ \\
Pimax $\left(\mathrm{cmH}_{2} \mathrm{O}\right)$ & $36.4(24.5-42.0)$ & $46.7(37.3-61.6)$ & 0.05 \\
TwPdi $\left(\mathrm{cmH}_{2} \mathrm{O}\right):$ & & & \\
$\quad$ & & & \\
$\quad$ Left & $5.6(1.9-8.3)$ & $4.7(3.3-6.8)$ & $\mathrm{ns}$ \\
$\quad$ Right & $4.9(3.4-6.7)$ & $5.0(3.3-6.8)$ & $\mathrm{ns}$ \\
$\quad$ Bilateral & $14.5(1.5-16.4)$ & $8.7(7.1-16.7)$ & $\mathrm{ns}$ \\
FRC $(\mathrm{ml} / \mathrm{kg})$ & $24(22-29)$ & $24(23-35)$ & $\mathrm{ns}$ \\
\hline
\end{tabular}

Data are demonstrated as median (range).

troschisis infants than their matched controls. No significant differences in cPdi and Pimax, however, were demonstrated between the groups. cPdi has previously been noted to be similar in AWD or CDH infants and controls (11). In the previous study (11), only cPdi was measured, cPdi is an effort-dependent test and the results can be submaximal and variable. In addition, maximal Pdi can vary considerably depending on whether the inspiratory effort is primarily the result of contraction of the diaphragm or whether the intercostals or accessory muscles are recruited (17). In the earlier study (11), the infants studied had a wide age range. In this study, we examined infants with a much narrower age range and matched the subjects and controls by gestational age. Gestational rather than postconceptional age was used in the matching, as the former correlates better with diaphragmatic force responses elicited by magnetic stimulation of the phrenic nerves (18). A possible explanation for our findings is that cPdi and Pimax, unlike TwPdi, do not reflect diaphragmatic performance alone. It has been commented (19) that assessment of Pimax does not permit discrimination between inspiratory muscle groups re- 
sults. The similarity of the cPdi and Pimax of the CDH and gastroschisis infants to those of their matched controls suggests that other inspiratory muscle groups may compensate for their impaired diaphragmatic function as occurs in patients with diaphragm dysfunction after liver transplantation $(20,21)$.

The magnitude of the difference in diaphragmatic function in $\mathrm{CDH}$ and gastroschisis infants. compared with controls was relatively small. The controls had all been admitted to the neonatal unit and thus cannot be considered "healthy." They were, however, only studied when no longer requiring supplementary oxygen and had not been exposed to prolonged periods of immobilization or malnutrition or other factors that might influence diaphragmatic function. Thus, we feel they were an appropriate control group. At the time of study, the $\mathrm{CDH}$ and AWD infants did not require positive pressure support and were thus not obviously clinically compromised by the poorer diaphragm function. All the infants were studied when awake or during quiet sleep, when patients with diaphragm dysfunction may be asymptomatic. Nocturnal hypoxia associated with diaphragmatic dysfunction occurs during REM sleep when there is intercostal and accessory respiratory muscle inhibition. The intercostals muscles exhibit both phasic and tonic inhibition; paradoxical inward motion of the rib cage during inspiration occurs when their stabilizing effect is inhibited and, to achieve the same tidal volume, the diaphragm must shorten twice as much as during quiet sleep (22). Hence, during REM sleep the diaphragmatic work of breathing is increased.

A 90-mm double circular coil was used for magnetic stimulation (Fig. 1), as it allows optimal positioning of the coil on the neck, and the magnetic field strength, depth of penetration ,and induced current in the tissues are of sufficient magnitude to produce supramaximal stimulation of the phrenic nerves using an anterolateral approach. The size and coil design and the ability to apply the coil to the required site of stimulation all influence the suitability of a coil to a particular application. Size and geometry of the coil are important as large coils have lower magnetic fields than small coils but higher depths of penetration. Strength and shape of the magnetic field and depth of penetration affect the current induced in the tissue and it is the size, waveform, and shape of the induced current that are the most important considerations in magnetic nerve stimulation. In adults, the most suitable coil for anterolateral stimulation is a 43-mm figure of eight double coil (23). The size and shape of this coil allows good positioning on the neck in adult subjects. The coils, however, are too large to be used in neonates.

Although cervical magnetic stimulation has been shown to cause significant extradiaphragmatic muscle depolarization and rib cage expansion $(24,25)$, anterolateral magnetic stimulation has been shown in adults to be a more specific stimulus (23). The shape and timing of the pressure waveforms using anterolateral magnetic stimulation in the current study were similar to the results obtained in adults (23), suggesting little coactivation of other respiratory muscles. It is also unlikely that coactivation of the contralateral phrenic nerve occurred during unilateral stimulation. Contralateral phrenic nerve stimulation would result in increases in the amplitude of the pressure response elicited by unilateral magnetic stimulation at increasing stimulus intensities, as more and more phrenic nerve fibers on the contralateral side are depolarized. We have previously demonstrated a clear plateau in unilateral TwPdi, with increasing stimulator output suggesting that contralateral phrenic nerve stimulation does not occur (12). Diaphragm EMG activity, recorded using an esophageal electrode in three adult patients with unilateral diaphragm paralysis, was absent when stimulating the affected side but present when stimulating the normal side, which suggests that cross-activation does not occur (26). Phrenic nerve stimulation in adults is commonly performed during a momentary occlusion of the airway to obtain a quasi-isometric contraction of the diaphragm. A momentary occlusion is difficult to perform in spontaneously breathing infants with a rapid respiratory rate. We have, however, previously demonstrated no significant difference in TwPdi when the measurement was performed with the airway occluded or unoccluded, suggesting any loss of pressure due air flow and therefore additional volume change was negligible (12).

Respiratory inductance plethysmography was not used and hence chest wall distortion could not be completely excluded, but no obvious chest wall distortion was noted.

Also, although sleep state was not formally assessed, the infants were only studied during periods of quiet breathing and, when asleep, when rapid eye and gross body movements were absent, thus avoiding the influence of REM sleep when intercostals muscle activity is lost and rib cage distortion occurs (22). Carbon dioxide was not administered. The infants started crying spontaneously when the face mask was applied. We have previously demonstrated that maximal airway and transdiaphragmatic pressures can be reproducibly measured during spontaneous crying, with coefficients of variation of $12 \%$ and $7 \%$, respectively (27).

The static and dynamic pressure responses of the balloon catheters and associated pressure transducers were assessed and validated before testing. No damping of the twitch pressure response occurred. In addition, comparison with cathetermounted microtransducers indicated no difference in the twitch pressure response between the two techniques. The balloon catheters used in the study, however, are smaller in diameter than those suggested by American Thoracic Society/European Respiratory Society guidelines on respiratory muscle testing (28), but the same type of balloon was used in both the subjects and the controls and thus the comparison of the results between the groups is valid.

A number of explanations for the lower TwPdi of the $\mathrm{CDH}$ and gastroschisis infants must be considered. Malnutrition has been shown to have a close correlation with poor respiratory muscle performance due to a reduced diaphragmatic weight $(29,30)$. Only a proportion of the AWD/CDH infants were enterally fed at the time of study and, although all had received total parenteral nutrition, this has not been shown to improve the development or affect the contractile properties of the diaphragm of premature baboons (31). The gastroschisis infants, as noted previously $(32,33)$, were significantly lighter than gestational age-matched controls. This impaired antenatal growth might have influenced diaphragmatic development. Overdistension can also impair muscle function, but none of 
the infants were hyperinflated (4). Indeed, the median FRC of the $\mathrm{CDH}$ patients was significantly lower than their matched controls, reflecting a degree of pulmonary hypoplasia, as has been previously described $(34,35)$. Another explanation is that the CDH/AWD infants were all exposed to immobilization perioperatively, which can result in reduction in mass and contractility of skeletal muscles. In animals, this may be evident after as little as $2 \mathrm{~d}$ of ventilation, even without use of neuromuscular blocking agents (36). The CDH/AWD infants were, however, studied once extubated and breathing spontaneously. Surgery, particularly thoracic and upper abdominal, can affect respiratory muscle function, but the effect is transitory (37), hence we studied infants at least a week after their final surgical intervention. The impact of surgical repair on ipsilateral diaphragm function in the $\mathrm{CDH}$ patients might last longer than $1 \mathrm{wk}$, but that would not explain our finding of lower right TwPdi in CDH infants who had had left-sided lesions. Unfortunately, the number of infants with a right-sided defect was too small to make statistical comparisons, but one infant with a right-sided defect had very low right TwPdi. Increased intra-abdominal pressure after surgical closure (38) impairs respiratory function of AWD infants (39), but again this effect is temporary, with improvements in compliance of the respiratory system being demonstrated by postoperative $\mathrm{d}$ 3. All of the AWD infants were studied at least 1 wk after surgical intervention.

We, therefore, speculate that the significantly lower right TwPdi of the CDH infants with left-side defects and the lower left and right TwPdi of the gastroschisis infants were, at least in part, due to poor antenatal diaphragmatic development. There are several explanations for impaired diaphragmatic development and, hence, antenatal lung growth in these infants. The low intra-abdominal pressure applied to the low part of the rib cage and the diaphragm may affect fetal diaphragmatic growth. The absence of abdominal support and the decreased radius of diaphragm curvature could affect fetal breathing and the strength of diaphragm contraction antenatally $(40,41)$. Stretch produced by the constant distending pressure and changes in thoracic shape during fetal breathing movements are the mechanical stimuli that promote growth of the fetal lung (42). We found no significant differences between the results of the exomphalos infants and their matched controls. This may, however, reflect a type II error. An alternative explanation is that the intra-abdominal pressure may not be low in such patients for, although the abdominal contents may be outside the cavity, they remain inside an intact sac (43). Assessment of the gastroschisis and $\mathrm{CDH}$ infants before operation would allow determination of the magnitude of diaphragmatic maldevelopment. The timing of initial surgical intervention in gastroschisis infants and the unstable preoperative condition and use of neuromuscular agents in $\mathrm{CDH}$ patients would, however, make such a study very difficult.

\section{CONCLUSION}

We conclude that $\mathrm{CDH}$ and gastroschisis infants do have impaired diaphragmatic function in the postoperative period. Prospective follow-up is necessary to reveal whether dia- phragm function impairment in gastroschisis or $\mathrm{CDH}$ infants is symptomatic under certain conditions and if it is associated with the chronic respiratory morbidity (2-4).

\section{REFERENCES}

1. Lund DP, Mitchell J, Kharasch V, Quigley S, Kuehn M, Wilson JM 1994 Congenital diaphragmatic hernia: the hidden morbidity. J Pediatr Surg 29:258-264

2. Muratore CS, Kharasch V, Lund DP, Sheils C, Friedman S, Brown C, Utter S, Jaksic T, Wilson JM 2001 Pulmonary morbidity in 100 survivors of congenital diaphrag matic hernia monitored in a multidisciplinary clinic. J Pediatr Surg 36:133-140

3. Nakayama DK, Mutich R, Motoyama EK 1992 Pulmonary dysfunction after primary closure of an abdominal wall defect and its improvement with bronchodilators. Pediatr Pulmonol 12:174-180

4. Thompson PJ, Greenough A, Nicolaides KH, Dykes E 1993 Impaired respiratory function in infants with anterior abdominal wall defects. J Pediatr Surg 28:664-666

5. Wigglesworth JS, Desai R 1979 Effect on lung growth of cervical cord section in the rabbit fetus. Early Hum Dev 3:51-65

6. Nagai A, Thurlbeck WM, Jansen AH, Loffe S, Chernick V 1988 The effect of chronic biphrenectomy on lung growth and maturation in feal lambs. Morphologic and morphometric studies. Am Rev Respir Dis 137:167-172

7. Liggins GC, Vilos GA, Campos GA, Kitterman JA, Lee CH 1981 The effect of spinal cord transection on lung development in fetal sheep. J Dev Physiol 3:267-274

8. Goldstein JD, Reid LM 1980 Pulmonary hypoplasia resulting from phrenic nerve agenesis and diaphragmatic amyoplasia. J Pediatr 97:282-287

9. Powell CA, Smiley BL, Mills JN, Vandenburgh HH 2002 Mechanical stimulation improves tissue-engineered human skeletal muscle. Am J Physiol Cell Biol 283:C1557-C1565

10. Cox VM, Williams PE, Wright H, James RS, Gillott KL, Young IS, Goldspink DF 2000 Growth induced by incremental static stretch in adult rabbit latissimus dorsi muscle. Exp Physiol 85:193-202

11. Scott CB, Nickerson BG, Sargent CW, Platzker ACG, Warburton D, Keens TG 1983 Developmental pattern of maximal transdiaphragmatic pressure in infants during crying. Pediatr Res 17:707-709

12. Rafferty GF, Greenough A, Dimitriou G, Kavvadia V, Laubscher B, Polkey MI, Harris ML, Moxham J 2000 Assessment of neonatal diaphragm function using magnetic stimulation of the phrenic nerves. Am J Respir Crit Care Med 162:23372340

13. Milner AD, Marsh MJ, Ingram DM, Fox GF, Susiva C 1999 Effects of smoking in pregnancy on neonatal lung function. Arch Dis Child Fetal Neonatal Ed 80:F8-F14

14. Dimitriou G, Greenough A 1995 Measurement of lung volume and optimal oxygenation during high frequency oscillation. Arch Dis Child Fetal Neonatal Ed 72:F180F183

15. Hey EN 1969 The relation between environmental temperature and oxygen consumption in the newborn baby. J Physiol 200:589-603

16. Dimitriou G, Greenough A, Laubscher B 1996 Lung volume measurements immediately after extubation and prediction of "extubation failure" in premature infants. Pediatr Pulmonol 21:250-254

17. De Troyer A, Estenne M 1981 Limitations of measurement of transdiaphragmatic pressure in detecting diaphragmatic weakness. Thorax 36:169-174

18. Dimitriou G, Greenough A, Moxham J, Rafferty GF 2003 Influence of maturation on infant diaphragm function assessed by magnetic stimulation of phrenic nerves. Pediatr Pulmonol 35:17-22

19. Syabbalo N 1998 Assessment of respiratory muscle function and strength. Postgrad Med J 74:208-215

20. Urmey WF, McDonald M 1992 Hemidiaphragmatic paresis during interscalene brachial plexus block: effects on pulmonary function and chest wall mechanics. Anesth Analg 74:352-357

21. Laroche CM, Carroll N, Moxham J, Green M 1988 Clinical significance of severe isolated diaphragm weakness. Am Rev Respir Dis 138:862-866

22. Muller NL, Bryan AC 1979 Chest wall mechanics and respiratory muscles in infants. Pediatr Clin North Am 26:503-516

23. Mills GH, Kyroussis D, Hamnegard CH, Wragg S, Moxham J, Green M 1995 Unilateral magnetic stimulation of the phrenic nerve. Thorax 50:1162-1172

24. Similowski T, Fleury B, Launois S, Cathala HP, Bouche P, Derenne JP 1989 Cervical magnetic stimulation: a new painless method for bilateral phrenic nerve stimulation in conscious humans. J Appl Physiol 67:1311-1318

25. Laghi F, Harrison MJ, Tobin MJ 1996 Comparison of magnetic and electrical phrenic nerve stimulation in assessment of diaphragmatic contractility. J Appl Physiol 80:1731-1742

26. Luo YM, Johnson LC, Polkey MI, Harris ML, Lyall RA, Green M, Moxham J 1999 Diaphragm electromyogram measured with unilateral magnetic stimulation. Eur Respir J 13:385-390

27. Dimitriou G, Greenough A, Rafferty GF, Moxham J 2001 Effect of maturity on maximal transdiaphragmatic pressure in neonates during crying. Am J Respir Crit Care Med 164:433-436

28. American Thoracic Society/European Respiratory Society 2002 ATS/ERS Statement on respiratory muscle testing. Am J Respir Crit Care Med 166:518-624

29. Arora NS, Rochester DF 1982 Respiratory muscle strength and maximal voluntary ventilation in undernourished patients. Am Rev Respir Dis 126:5-8

30. Goldberg AL, Odessey R 1972 Oxidation of amino acids by diaphragms from fed and fasted rats. Am J Physiol 223:1384-1391

31. Maxwell LC, Kuehl TJ, Meredith K, Gerstmann DR, Delemos RA 1994 Total parenteral nutrition does not improve diaphragm development in premature baboons. J Appl Physiol 77:43-50 
32. Raynor BD, Richards DA 1997 Growth retardation in fetuses with gastroschisis. J Ultrasound Med 16:13-16

33. Fries MH, Filly RA, Callen PW, Goldstein RB, Goldberg JD, Golbus MS 1993 Growth retardation in prenatally diagnosed cases of gastroschisis. J Ultrasound Med 12:583-588

34. Thibeault WD, Haney B 1998 Lung volume, pulmonary vasculature and factors affecting survival in congenital diaphragmatic hernia. Pediatrics 101:289-295

35. Nobuhara KK, Wilson JM 1996 Pathophysiology of congenital diaphragmatic hernia Semin Pediatr Surg 5:234-242

36. Le Bourdelles G, Viires N, Boczkowski J, Seta N, Pavlovic D, Aubier M 1994 Effect of mechanical ventilation on diaphragmatic contractile properties in rats. Am J Respir Crit Care Med 149:1539-1544

37. Siafakas NM, Mitrouska I, Argiana E, Bouros D, Georgopoulos D 1999 Surgery and the respiratory muscles. Thorax 54:458-465

38. Ein SH, Rubin SZ 1980 Gastroschisis: primary closure or silon pouch. J Pediatr Surg 15:549-552
39. Dimitriou G, Greenough A, Giffin FJ, Davenport M, Nicolaides KH 1996 Temporary impairment of lung function in infants with anterior abdominal wall defects undergoing surgery. J Pediatr Surg 31:670-672

40. Hershenson MB, Brouillette RT, Klemka C, Raffensperger JD, Poznanski AK, Hunt CE 1985 Respiratory insufficiency in newborns with abdominal wall defects. J Pediatr Surg 20:348-353

41. Praud JP, Trang TTH, Boule M, Delaperche MF, D'Allest AM, Gaultier C 1990 Exploration fonctionnelle respiratoire des ompaloceles. In: Beaufils, F, Aigrain, Y, Nivoche, Y (eds) Defauts congenitaux de la paroi abdominale. Arnette, Paris, pp $75-81$

42. Kitterman JA 1996 The effects of mechanical forces on fetal lung growth. Clin Perinatol 23:727-740

43. Headley BM, McDougall PN, Stokes KB, Dewan PA, Dargaville PA 2001 Left-lung-collapse bronchial deformation in giant omphalocele. J Pediatr Surg $36: 846-850$ 